\title{
Supplemental Effect of Astaxanthin in Broodstock Diets on the Quality of Yellowtail Eggs
}

\author{
Visuthi Verakunpiriya, ${ }^{* 1}$ Keiichi Mushiake, ${ }^{* 2}$ Kazutoshi Kawano, ${ }^{* 2}$ \\ and Takeshi Watanabe*1 \\ ${ }^{{ }_{1}}$ Laboratory of Fish Nutrition, Department of Aquatic Biosciences, \\ Tokyo University of Fisheries, Konan, Minato, Tokyo 108, Japan \\ ${ }^{*}$ Komame Station of Japan Sea-Farming Association, Komame, \\ Otsuki, Hata, Kochi 788-03, Japan
}

(Received February 3, 1997)

\begin{abstract}
Different levels of pure astaxanthin $(0,20,30$, and $40 \mathrm{ppm})$ were supplemented in soft-dry pellets (SDP), in order to clarify the effect of this carotenoid on the quality of eggs and spawning performance of yellowtail. Three-year-old fish of average body weight $6.1 \mathrm{~kg}$ were separately fed one of each test diet. The feeding experiment was carried out in cages for about 5 months prior to spawning. Seven males and 7 females from each test diet group were transferred to $65 \mathrm{~m}^{3}$ indoor spawning tanks to permit them to spawn spontaneously, while those which remained in the cages were artificially inseminated. Fish of both spawning investigations were induced to maturity by HCG injection (600 IU $/ \mathrm{kg}$-fish).

When the brood fish were allowed to spawn spontaneously, those fed SDP supplemented with 30 ppm astaxanthin gave superior results for total production, quality of eggs and the final number of normal larvae. These observations were identical to those from the artificially inseminated group. Thus, the supplementation of astaxanthin in SDP was found to be effective for broodstock yellowtail and seemed to be optimal at around $30 \mathrm{ppm}(30 \mathrm{mg} / \mathrm{kg}$-diet); beyond which the quality of eggs diminished.
\end{abstract}

Key words: astaxanthin, egg quality, yellowtail, broodstock diets

Our preliminary work ${ }^{1)}$ on "Nutrition and Reproductive Performance of Yellowtail" indicated that soft-dry pellets (SDP) could be employed as diets for the broodstock. On the basis of egg quality ${ }^{1)}$ and chemical analysis, ${ }^{2}$ SDP proved superior to both fresh or frozen raw fish and moist pellets generally used for broodstock rearing. Krill meal, which is usually supplemented in the practical SDP to enhance skin pigmentation in yellowtail, ${ }^{3)}$ was postulated to be the effective constituent, specifically the astaxanthin in the meal, as demonstrated in red sea bream broodstock diets. ${ }^{4}$ Results obtained from broodstock fed SDP containing $10 \%$ krill meal in the preliminary study ${ }^{1)}$ and those from fish fed SDP without supplementation of krill meal in a later experiment ${ }^{\text {s) }}$ were comparable in spawning performance, egg quality, and carotenoid content in eggs. This was because the latter SDP was found to contain carotenoids almost at an identical level as the former SDP. The same experiment ${ }^{5)}$ revealed that it was not advisable to include high amounts of krill meal because it seemed to impair the spawning performance and the quality of the eggs, probably due to the excess amount of astaxanthin or components other than carotenoids contained in krill meal. ${ }^{* 3}$

With this background, the present study examined the effect of astaxanthin, the predominant carotenoid component in krill meal, () on the spawning performance and quality of yellowtail eggs. A synthetic carotenoid was supplemented instead of krill meal in the practical SDP and fed to the three-year-old yellowtail prior to their spawning. The factors relating to spawning were observed and the results are discussed in this paper.

\section{Materials and Methods}

\section{Experimental Diets}

Table 1 shows the composition of the basal SDP used for all the test diets in this experiment, including the scheme of carotenoid supplementation. Basically, the formulation of the SDP was almost the same as in the previous experiment, ${ }^{1,5)}$ and all the test diets were prepared as soft-dry pellets ${ }^{7^{7}}$ by Sakamoto Fish Feed Co., Ltd., using a twin screw extruder (Buhler Co., Ltd.). The basic SDP was formulated to contain about $46 \%$ crude protein, in which fish meal was the main protein source in combination with defatted soybean meal, and about $24 \%$ crude lipid mainly derived from feed oil (pollack liver oil).

To examine the effect of pure carotenoids on the spawning performance and quality of eggs of yellowtail, astaxanthin which was hypothesized to be the effective component in krill meal was supplemented in that basal SDP at the levels of $0,20,30$, and $40 \mathrm{ppm}(0,20,30$, and $40 \mathrm{mg}$ astaxanthin per $\mathrm{kg}$-diet, respectively) and are designated as 0-Astx, 20-Astx, 30-Astx, and 40-Astx, respectively. The synthetic carotenoid, Carophyll Pink ${ }^{\circledR}$ (Nippon Roche), which contained $8 \%$ astaxanthin, was employed. The ana-

${ }^{*}$ Gyorui Youshoku Kankyo Jikaosen Boushi Gijitsu Kaihatsu Kenkyu (Haigou Shiryou) Nendo Honkokusho: Kouchi-ken Suisan Shikenjou 1981, pp. 1-38 (in Japanese). 
Table 1. Composition of the basal soft-dry pellets (SDP) and scheme of the experimental diets

\begin{tabular}{lr}
\hline A: Composition of basal SDP (\%) \\
Fish meal (sand lance) \\
Defatted soybean meal & 56.0 \\
Wheat flour & 4.0 \\
Potato starch & 10.0 \\
Vitamin and mineral mixtures & 6.0 \\
Feed oil & 6.2 \\
\hline B: Scheme of the experimental diets & 16.8 \\
\hline SDP $\quad+0$ ppm Astaxanthin $\rightarrow$ 0-Astx \\
\end{tabular}

- Carophyll Pink (Nippon Roche) containing $8 \%$ astaxanthin.

Table 2. Proximate composition and carotenoid contents and their composition in the experimental diets

\begin{tabular}{|c|c|c|c|c|}
\hline & 0 -Astx & 20-Astx & 30-Astx & 40-Astx \\
\hline \multicolumn{5}{|l|}{ A: Proximate composition (\%) } \\
\hline Crude protein & 43.04 & 43.81 & 43.13 & 43.72 \\
\hline Crude lipid & 22.16 & 22.64 & 22.51 & 19.34 \\
\hline Crude ash & 8.81 & 9.06 & 8.82 & 8.89 \\
\hline Moisture & 7.52 & 5.51 & 6.93 & 8.07 \\
\hline \multicolumn{5}{|l|}{ Dry matter basis weight } \\
\hline Crude protein & 46.54 & 46.36 & 46.34 & 47.56 \\
\hline Crude lipid & 23.96 & 23.96 & 24.19 & 21.04 \\
\hline $\mathrm{VE}(\mu \mathrm{g} / \mathrm{g})$ & 295.6 & 253.1 & 248.7 & 273.2 \\
\hline Gross energy $(\mathrm{kcal} / 100 \mathrm{~g})^{*_{1}}$ & 532.3 & 547.5 & 535.7 & 511.2 \\
\hline \multicolumn{5}{|c|}{ B: Carotenoid contents and their composition ( $\mathrm{mg} / \mathrm{kg}$ diet) } \\
\hline Astaxanthin (free) & 0.1 & 15.1 & 30.6 & 37.4 \\
\hline Astaxanthin (esters) & 2.3 & 2.2 & 2.3 & 2.2 \\
\hline Xanthophylls*2 & 0.1 & 0.1 & 0.3 & 0.6 \\
\hline $\begin{array}{l}\text { Astaxanthin content } \\
\text { (ppm in diets) }\end{array}$ & 2.4 & 17.3 & 32.9 & 39.6 \\
\hline
\end{tabular}

lytical data of the experimental diets such as proximate composition and fatty acid composition, which were determined by the methods described previously, ${ }^{2)}$ and carotenoid contents and their composition, which were kindly analyzed by Vitamins \& Fine Chemicals Division, Nippon Roche Research Center (Nippon Roche K.K.), are summarized in Tables 2 and 3 . On the basis of nutrient requirements of yellowtail, all the test diets contained sufficient amounts of protein (about $46 \%$ ), lipid (about $24 \%$ ) and gross energy (about $500 \mathrm{kcal} / 100 \mathrm{~g}$-diet). ${ }^{7-9)}$ The test diets were similar in fatty acid composition and essential fatty acid (EFA) profiles. They contained around $30-31 \%$ each of saturated and mono-unsaturated fatty acids, about 24$25 \%$ n-3 highly unsaturated fatty acids (n-3 HUFA), and about $11 \%$ each of eicosapentaenoic acid (EPA; 20:5n-3) and docosahexaenoic acid (DHA; 22:6n-3). The ratio of DHA to EPA, which has been demonstrated to have an important role during the development of gonads in yellowtail brood fish, ${ }^{2)}$ was kept at the same level of around 0.9 for all the test diets. On the basis of the EFA profile during gonadal development of brood fish, embryogenesis, and that of yolksac larvae during the endogenous stage, the above composition seems to be adequate for the needs of
Table 3. Distribution of fatty acids in the experimental diets

\begin{tabular}{|c|c|c|c|c|}
\hline $\begin{array}{r}\text { Fatty acid } \\
(\% \text { area })\end{array}$ & 0 -Astx & 20-Astx & 30-Astx & 40-Astx \\
\hline $14: 0$ & 6.41 & 6.42 & 6.63 & 6.32 \\
\hline $14: 1$ & 0.24 & 0.24 & 0.25 & 0.17 \\
\hline $15: 0$ & 0.59 & 0.58 & 0.60 & 0.57 \\
\hline $16: 0$ & 18.50 & 18.67 & 18.90 & 18.63 \\
\hline $16: \ln -7$ & 6.62 & 6.65 & 6.80 & 6.47 \\
\hline $17: 0$ & 0.46 & 0.47 & 0.46 & 0.44 \\
\hline $16: 3 n-6$ & 0.97 & 0.94 & 0.97 & 0.91 \\
\hline $16: 3 n-3$ & 0.19 & 0.20 & 0.19 & 0.19 \\
\hline $16: 4 n-1$ & 0.86 & 0.83 & 0.90 & 0.87 \\
\hline $18: 0$ & 3.94 & 3.95 & 3.88 & 3.84 \\
\hline $18: 1 n-9$ & 12.57 & 12.80 & 12.76 & 12.70 \\
\hline $18: 1 \mathrm{n}-7$ & 2.97 & 3.09 & 3.06 & 2.97 \\
\hline $18: \ln -5$ & 0.18 & 0.18 & 0.19 & 0.18 \\
\hline $18: 2 n-6$ & 2.73 & 2.80 & 2.87 & 3.58 \\
\hline $18: 3 n-6$ & 0.12 & 0.09 & 0.11 & 0.12 \\
\hline $18: 3 n-3$ & 0.87 & 0.87 & 0.88 & 0.95 \\
\hline $18: 4 n-3$ & 1.83 & 1.81 & 1.88 & 1.88 \\
\hline $18: 4 n-1$ & 0.15 & 0.14 & 0.15 & 0.14 \\
\hline $20: 0$ & 0.32 & 0.32 & 0.30 & 0.30 \\
\hline $20: \ln -11$ & 1.29 & 1.38 & 1.32 & 1.26 \\
\hline $20: \ln -9$ & 2.62 & 2.70 & 2.64 & 2.71 \\
\hline $20: 1 \mathrm{n}-7$ & 0.29 & 0.31 & 0.29 & 0.33 \\
\hline $20: 2 n-9$ & 0.10 & 0.10 & 0.10 & 0.10 \\
\hline $20: 2 n-6$ & 0.21 & 0.21 & 0.20 & 0.20 \\
\hline $20: 3 n-6$ & 0.10 & 0.10 & 0.09 & 0.09 \\
\hline $20: 4 n-6$ & 1.23 & 1.16 & 1.16 & 1.13 \\
\hline $20: 3 n-3$ & 0.09 & 0.17 & 0.09 & 0.09 \\
\hline $20: 4 n-3$ & 0.66 & 0.65 & 0.62 & 0.64 \\
\hline $20: 5 n-3$ & 11.64 & 11.32 & 11.28 & 11.19 \\
\hline $22: 0$ & 0.09 & tr & $\operatorname{tr}$ & tr $\mathbf{r}$ \\
\hline $22: \ln -(13+11)$ & 3.28 & 3.50 & 3.29 & 3.46 \\
\hline $22: \ln -9$ & 0.40 & 0.43 & 0.40 & 0.41 \\
\hline $22: 1 \mathrm{n}-7$ & 0.09 & tr & $\mathrm{tr}$ & $\operatorname{tr}$ \\
\hline $22: 4 n-9$ & 0.43 & 0.41 & 0.40 & 0.40 \\
\hline $22: 4 n-6$ & $\mathrm{tr}^{* 1}$ & $\mathrm{tr}$ & tr & $\mathbf{t r}$ \\
\hline $22: 5 n-6$ & 0.35 & 0.30 & 0.31 & 0.30 \\
\hline $22: 4 n-3$ & $\mathrm{ND}^{* 2}$ & ND & ND & ND \\
\hline $22: 5 n-3$ & 2.01 & 1.94 & 1.83 & 1.85 \\
\hline $22: 6 n-3$ & 10.68 & 10.31 & 10.12 & 10.85 \\
\hline$\Sigma$ Saturate & 30.31 & 30.41 & 30.77 & 30.10 \\
\hline$\Sigma$ Monoene & 30.55 & 31.28 & 31.00 & 30.66 \\
\hline$\Sigma \mathrm{n}-3 \mathrm{HUFA}$ & 25.08 & 24.39 & 23.94 & 24.62 \\
\hline DHA/EPA & 0.92 & 0.91 & 0.90 & 0.97 \\
\hline
\end{tabular}

*1 Trace amount $(<0.005)$.

*: Not detected.

the different developmental stages. ${ }^{2,10,11)}$

The content of astaxanthin in each test diet was proportional to the amount of the supplemented synthetic astaxanthin; the 0-Astx, 20-Astx, 30-Astx, and 40-Astx diets contained $2.4,17.3,32.9$, and $39.6 \mathrm{ppm}$, respectively. The composition of carotenoids in the SDP supplemented with different levels of synthetic astaxanthin was similar, free astaxanthin being the main component (87.3-94.4\%), followed by astaxanthin esters $(5.6-12.7 \%)$, and trace amounts of xanthophylls. On the other hand, the main component in the SDP without supplementation of synthetic astaxanthin (0-Astx) was esterified astaxanthin $(95.8 \%)$ whilst the others such as free astaxanthin and xanthophylls were only present in traces. The little amount of astaxanthin in the unsupplemented SDP may have been 
directly derived from protein and/or lipid sources (fish meal and feed oil).

\section{Feeding of Yellowtail Broodstock}

Three-year-old yellowtail, (Seriola quinqueradiata TEMMINCK \& SCHLEGEL) having a body weight of $6.1 \pm 0.9 \mathrm{~kg}$ and fork length of $69.1 \pm 2.9 \mathrm{~cm}$ (condition factor: 18.5 ) were used. Forty fish each (approximately 20 males and 20 females) were separately stocked into $5 \times 10 \times 5 \mathrm{~m}$ floating net cages that were installed at the inner sea of the Komame bay, close to the Komame Station (Kochi Prefecture) of Japan Sea-Farming Association (JASFA). Each of the four broodstock groups was offered the designated test diets at a ration of about $2.5 \%$ of their body weight, once every other day for about 5 months prior to spawning. The water temperature during the feeding period (November 1995-April 1996) fluctuated between 21.7 and $9.8^{\circ} \mathrm{C}$ (average: $17.5 \pm 1.8^{\circ} \mathrm{C}$ ).

Investigation of Spawning and Evaluation of Egg Quality

Assessment of spawning was made after completing the feeding experiment. Healthy fish selected from each experimental lot were induced hormonally and either allowed to spawn spontaneously in $65 \mathrm{~m}^{3}$ indoor tanks or inseminated artificially at the cage site.

Spontaneous spawning: Seven males and an equal number of females having an average body weight of about 8 $\mathrm{kg}$ were selected from each test diet group to induce maturity and stimulate spawning. The fish were injected with HCG (human chorionic gonadotropin) at a dosage of 600 $\mathrm{IU} / \mathrm{kg}$-fish, ${ }^{12)}$ and they were immediately transferred and stocked separately into the $65 \mathrm{~m}^{3}$ indoor spawning concrete tanks on land. Spawning conditions such as water temperature, water exchange and light intensity were controlled as described elsewhere. ${ }^{1,12-14)}$

Eggs produced by female brood fish of each test diet group were collected at $09: 00 \mathrm{~h}$ and then at $17: 00 \mathrm{~h}$ to enumerate the daily rate, until no further eggs were laid. The degree of success of spawning was determined on the basis of the number of eggs produced, the rate of buoyant and fertilized eggs at morula stage, diameter of eggs and oil globules etc. Buoyant eggs, which are generally assumed to be useful for the evaluation of egg quality, were then stocked into hatching nets in order to assess the rate of hatching and to observe the nature of the hatched larvae. Survival activity index, which indicates the response of the larvae under starvation; ${ }^{13)}$ was also determined. Under commercial mariculture operations, the larvae that can reach the stage of hatchery reared juveniles, ready for release, are termed "normal larvae". In the present experiment, the calculation was carried out for the normal larvae obtained, based on total egg output using the formula described in the footnote of Table 5.

Details on egg collection and evaluation, investigation of egg quality and assessment of hatched larvae were described elsewhere. ${ }^{1,12-14)}$

Artificial insemination: The three male and three female brood fish selected from each test diet group for artificial insemination were also induced to mature by HCG injection at the same dosage used for the spontaneous spawning method. Normally, the yellowtail brood fish reached maturity within $48 \mathrm{~h}$ after the injection of 600 IU-HCG/ $\mathrm{kg}$-fish, ${ }^{12)}$ and the stage of maturity was confirmed either by canulation or gentle stripping, before inseminating them. Milt was pooled from all the male brood fish of each test diet group and then preserved in an ice-cooler box (temperature $<5^{\circ} \mathrm{C}$ ). Ovulating eggs of individual female brood fish of each test diet group were obtained by abdominal stripping and they were fertilized separately with spermatozoa from the same group by the dry method as described by Mushiake et al. ${ }^{12}$ The production was assessed as described earlier for the spontaneous spawning.

\section{Results and Discussion}

\section{Feed Performance and Status of the Broodstock Yellow-} tail

It has been established that SDP are acceptable, palatable, and digestible by yellowtail and produce good growth. ") The results obtained from our preliminary study ${ }^{1 \text { " }}$ also proved that the fish could be cultured with this diet type from the juvenile stage under captivity. They first spawned within 3 years, even when they were relatively small in size (average body weight $4.3 \mathrm{~kg}$, fork length 59.4 $\mathrm{cm}$, and condition factor 20.5) compared to $8 \mathrm{~kg}$ spawners used commonly for seed-production operations. ${ }^{(2-14)}$ The efficacy of the SDP was further demonstrated in a later study, ${ }^{5}$ when the same broodstock yellowtail spawned for the second year in succession.

Table 4 shows the status of broodstock used for the spontaneous spawning. The body weight of the male brood fish ranged from $7.5-8.4 \mathrm{~kg}$, the fork length $70.4-$ $72.9 \mathrm{~cm}$ and the condition factor $20.9-22.2$. The corresponding figures for the female fish were $8.0-8.3 \mathrm{~kg}$ body weight, $70.8-72.4 \mathrm{~cm}$ fork length, and $21.0-22.5$ condition factor. On the basis of fish size and their condition factors, it was considered that the inclusion of synthetic astaxanthin, up to $40 \mathrm{ppm}$, in the SDP fed to yellowtail broodstock for about 5 months did not produce any negative effects on their growth or gonadal development. They grew from about $6.1 \mathrm{~kg}$ body weight at the initiation of the feeding experiment to between 7.5 and $8.4 \mathrm{~kg}$ just before spawning. The condition factor of the fish in this experiment was high compared to those of wild and cultured yellowtail broodstock of the same age. ${ }^{12-14}$ Under hormone

Table 4. Status of the broodstock used for spontaneous spawning

\begin{tabular}{lrrrr}
\hline & \multicolumn{4}{c}{ Experimental groups } \\
\cline { 2 - 5 } & 0-Astx & 20-Astx & 30-Astx & 40-Astx \\
\hline Male fish* & & & & \\
$\quad$ Body weight (kg) & $8.4 \pm 1.2$ & $7.5 \pm 0.6$ & $8.2 \pm 1.0$ & $7.6 \pm 1.2$ \\
$\quad$ Fork length (cm) & $72.2 \pm 3.5$ & $70.4 \pm 2.7$ & $72.9 \pm 2.7$ & $71.3 \pm 3.6$ \\
$\quad \begin{array}{l}\text { Condition factor }{ }^{* 2} \\
\text { Female fish }\end{array}$ & $22.2 \pm 1.9$ & $21.5 \pm 1.7$ & $21.1 \pm 1.4$ & $20.9 \pm 0.7$ \\
Body weight (kg) & $8.0 \pm 0.8$ & $8.3 \pm 0.5$ & $8.0 \pm 0.4$ & $8.1 \pm 1.4$ \\
Fork length (cm) & $70.8 \pm 1.4$ & $71.6 \pm 2.5$ & $72.4 \pm 1.3$ & $72.2 \pm 3.5$ \\
Condition factor & $22.5 \pm 1.8$ & $22.5 \pm 1.3$ & $21.0 \pm 0.8$ & $21.5 \pm 2.2$ \\
\hline
\end{tabular}

${ }^{*}$ Mean $\pm S D, n=5$.

$*_{2}$ Condition factor $=\frac{\mathrm{BW}}{\mathrm{FL}^{3}} \times 1000$. 
stimulation, they spawned normally during the spawning season (March-May).

\section{Appraisal of Spontaneous Spawning}

Entire Spawning Period: The results for the entire period of spontaneous spawning of yellowtail brood fish fed SDP supplemented with the different levels of synthetic astaxanthin for about 5 months prior to their spawning are summarized in Table 5. The injection of $\mathrm{HCG}$ at a dosage of $600 \mathrm{IU} / \mathrm{kg}$-fish stimulated the spawning in all the treatments and female brood fish laid their eggs around 48-52 hrs after hormone injection as usual (Fig. 1). Although the average size of female brood fish did not differ among the groups, the 0-Astx, 20-Astx, 30-Astx, and 40-Astx groups produced eggs for $6,4,7$, and 5 days, respectively. The corresponding figures for total eggs produced throughout the spawning period were $1755 \times 10^{3}, 503 \times 10^{3}, 1786 \times 10^{3}$, and $1285 \times 10^{3} \mathrm{eggs} /$ female $\left(219 \times 10^{3}, 61 \times 10^{3}, 224 \times 10^{3}\right.$, and $158 \times 10^{3} \mathrm{eggs} / \mathrm{kg}$-female), respectively. Based on the total eggs produced, the rates of buoyant eggs were 31.4 , $51.6,52.6$, and $21.2 \%$; the rates of fertilized eggs were $28.9,41.2,47.4$, and $15.5 \%$; and the rates of normal eggs having one oil globule were $28.7,47.6,49.4$, and $19.3 \%$, respectively. The results over the entire spawning period showed that brood fish fed the SDP supplemented with astaxanthin produced a greater number of normal eggs comprising high percentages of buoyant and fertilized eggs compared to the figures usually obtained during seed production operations at the Komame Station (JASFA). ${ }^{12-14)}$
These values reached an optimum when the supplemental level was $30 \mathrm{ppm}$ astaxanthin. Supplementation of 40 ppm astaxanthin in the SDP seemed to be an over-dose because the quality of eggs deteriorated (Figs. 1 and 2). There was a general decrease in the sizes of eggs and oil globules, as the spawning advanced in all the treatments (Fig. 3); the values obtained from the 30-Astx group were superior. Although, the sizes differed among the groups, the difference was not large, and the values were comparable to those obtained from wild or raw fish fed yellowtail. ${ }^{1,12-14)}$

Basically, animals are unable to synthesize carotenoids de novo. The organisms that are able to do so are certain microorganisms, fungi, algae, and higher plants. Animals, including marine fish, can incorporate or deposit carotenoids in their skin, and flesh, after deriving them from either the food chain or directly from the carotenoid-supplemented diets. The degree of incorporation and/or deposition is presumed to be directly linked to the amount consumed. In this study, the eggs produced by brood fish were pale yellow in color when fed 0-Astx diet, yellow in the case of the 20-Astx group, darker yellow in the 30-Astx group, whilst the intensity of the yellow color for the 40 Astx group was comparable to that of the 20-Astx group. The visible yellow color of yellowtail eggs is known to be characterized by zeaxanthin, which is found to be the main carotenoid component. ${ }^{15)}$ In addition, zeaxanthin in eggs was available from the bioconversion of astaxanthin via broodstock diets. ${ }^{2)}$ In this experiment, the amount of

Table 5. Cumulative spawning performance of yellowtail brood fish fed the SDP supplemented with different levels of astaxanthin for about 5 months prior to spawning*1

\begin{tabular}{|c|c|c|c|c|c|c|}
\hline \multirow{2}{*}{$\begin{array}{l}\text { Experimental } \\
\text { factors }\end{array}$} & & & \multicolumn{4}{|c|}{ Experimental groups } \\
\hline & & & 0 -Astx & 20-Astx & 30-Astx & 40 -Astx \\
\hline Average $\mathrm{BW}$ of female & & $(\mathrm{kg})$ & 8.00 & 8.26 & 7.97 & 8.12 \\
\hline Number of spawners & & (male:female) & $7: 7$ & $7: 7$ & $7: 7$ & $7: 7$ \\
\hline Spawning duration & & (days) & 6 & 4 & 7 & 5 \\
\hline \multicolumn{7}{|l|}{ Eggs } \\
\hline \multirow{2}{*}{ Eggs produced ${ }^{* 2}$} & & $\left(\times 10^{3} /\right.$ female $)$ & 1755 & 503 & 1786 & 1285 \\
\hline & & ( $\times 10^{3} / \mathrm{kg}$-female $)$ & 219 & 61 & 224 & 158 \\
\hline Buoyancy rate & & $(\%)$ & 31.4 & 51.6 & 52.6 & 21.2 \\
\hline \multirow[t]{2}{*}{ Fertilization rate among: } & -Total eggs produced & $(\%)$ & 28.9 & 41.2 & 47.4 & 15.5 \\
\hline & -Buoyant eggs & $(\%)$ & 91.8 & 79.8 & 90.1 & 73.4 \\
\hline \multirow{2}{*}{ Normal eggs ${ }^{* 3}$ among: } & -Total eggs produced & $(\%)$ & 28.7 & 47.6 & 49.4 & 19.3 \\
\hline & -Buoyant eggs & $(\%)$ & 91.3 & 92.4 & 94.0 & 91.1 \\
\hline Egg diameter ${ }^{*_{4}}$ & & $(\mu \mathrm{m})$ & $1110 \pm 43$ & $1131 \pm 46$ & $1154 \pm 37$ & $1106 \pm 53$ \\
\hline Oil-globule diameter ${ }^{* 4}$ & & $(\mu \mathrm{m})$ & $288 \pm 18$ & $296 \pm 19$ & $306 \pm 10$ & $293 \pm 22$ \\
\hline \multicolumn{7}{|l|}{ Larvae } \\
\hline \multirow[t]{3}{*}{ Rate of hatching among: } & -Total eggs produced & $(\%)$ & 21.2 & 40.0 & 45.2 & 13.7 \\
\hline & -Buoyant eggs & $(\%)$ & 67.6 & 77.6 & 85.9 & 64.9 \\
\hline & -Fertilized eggs & $(\%)$ & 73.6 & 97.2 & 95.3 & 88.4 \\
\hline \multirow{2}{*}{ Larvae obtained } & & $\left(\times 10^{3} /\right.$ female $)$ & 373 & 201 & 806 & 177 \\
\hline & & $\left(\times 10^{3} / \mathrm{kg}\right.$-female $)$ & 47 & 24 & 101 & 22 \\
\hline Survival activity index & & (range) & $10.1-18.0$ & 8.4 & $12.0-21.9$ & $10.8-17.0$ \\
\hline Normal larvae obtained*5 & & $(\%)$ & 19.4 & 36.9 & 42.6 & 12.5 \\
\hline
\end{tabular}

- This data was obtained from the entire period of spawning.

*2 Average values from 7 females which were stocked in each spawning tank

${ }^{3}$ Eggs with one oil globule.

$*$ Mean $\pm S D, n=25$.

(3uon 
astaxanthin supplemented in SDP and subsequently fed to broodstock affected the intensity of pigmentation of the eggs, but peaked at the $30 \mathrm{ppm}$ astaxanthin level. Therefore, it is thought that yellowtail have only limited ability
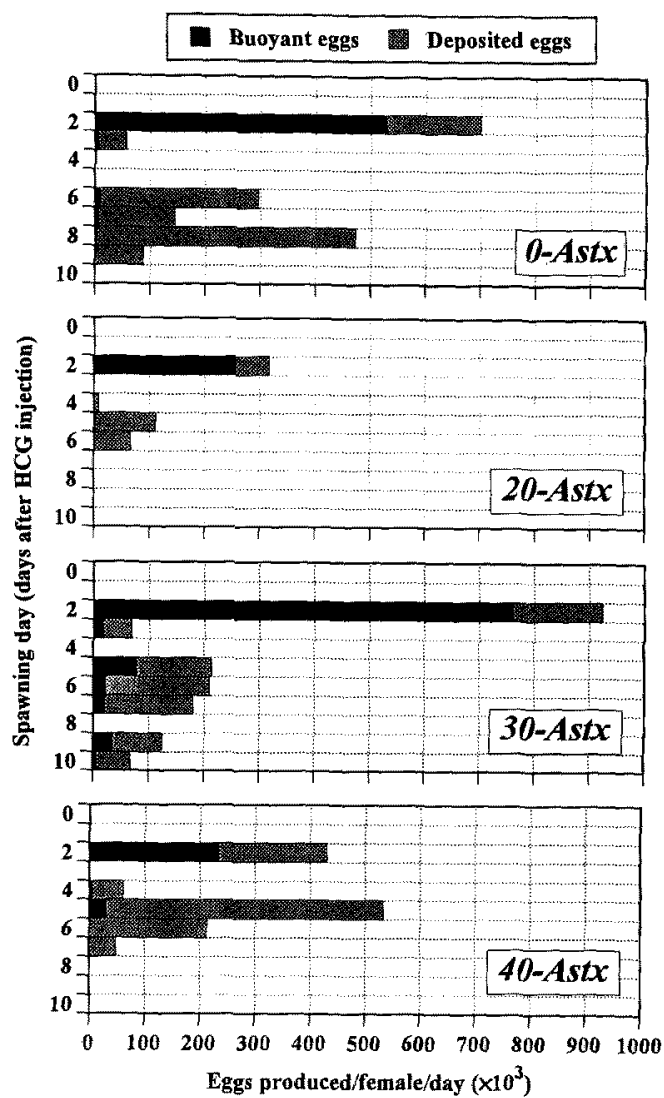

Fig. 1. Egg production of yellowtail brood fish fed SDP supplemented with different levels of astaxanthin. to utilize this carotenoid directly. However, since this was a qualitative study, it would be better understood if assessed chemically based on the utilization and bioconversion of astaxanthin.

The results of evaluation of eggs in terms of the numbers of larvae obtained, their hatching rate and the rate of normal larvae out of total eggs produced are summarized in Table 5. The rates of hatched larvae were $21.2,40.0$, 45.2 , and $13.7 \%$; the number of larvae obtained per female were $373 \times 10^{3}, 201 \times 10^{3}, 806 \times 10^{3}$, and $177 \times 10^{3}$ $\left(47 \times 10^{3}, 24 \times 10^{3}, 101 \times 10^{3}\right.$, and $22 \times 10^{3} \mathrm{larvae} / \mathrm{kg}$-female); the rates of normal larvae obtained were $19.4,36.9$, 42.6 , and $12.5 \%$; and the ranges of survival activity index were 10.1-18.0, 8.4 (data from the first day only), 12.021.9, and 10.8-17.0, for the 0,20,30, and 40-Astx groups, respectively. The results revealed that the final seed production was elevated by feeding broodstock yellowtail with SDP supplemented with astaxanthin. Fish fed 30-Astx diet

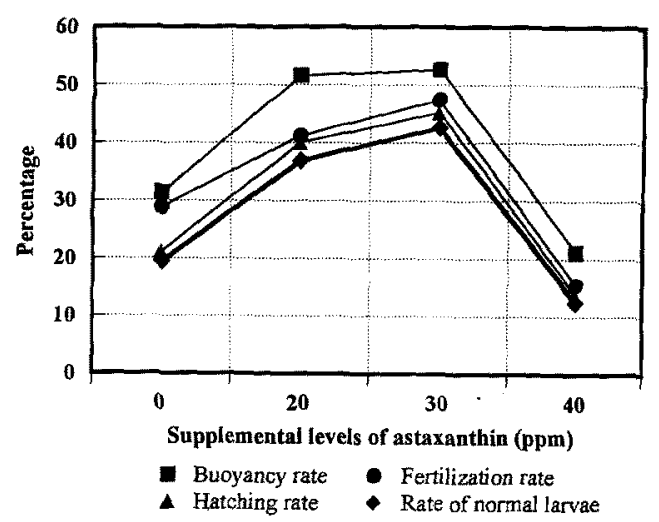

Fig. 2. Quality of eggs obtained during the entire period of spontaneous spawning from yellowtail brood fish fed diets containing different supplemental levels of astaxanthin.

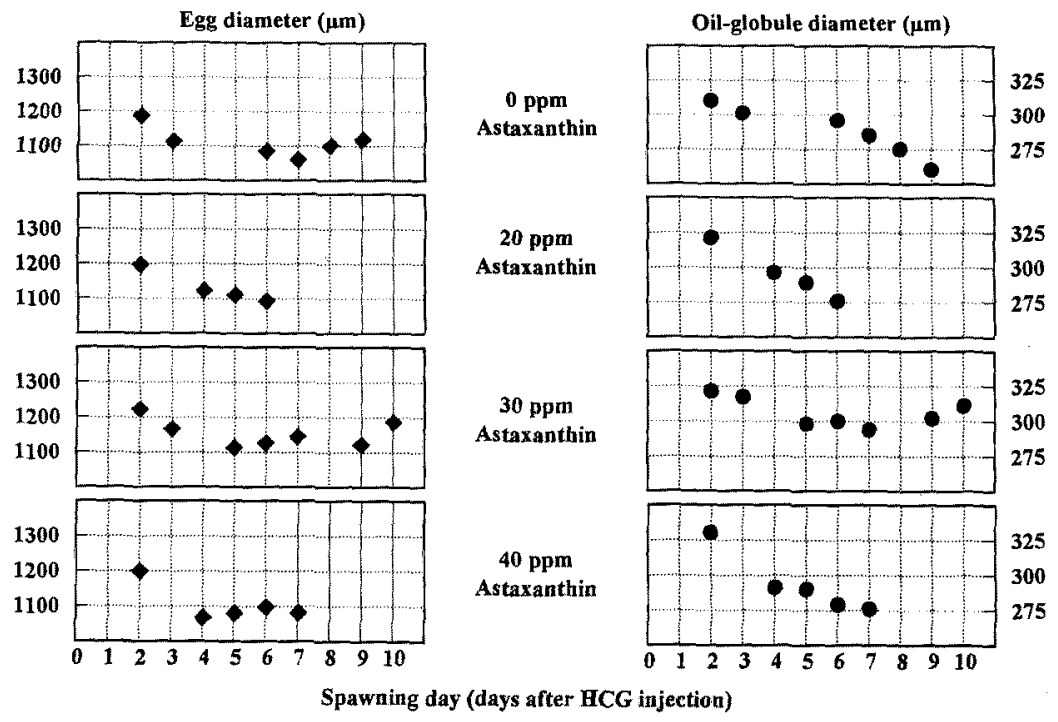

Fig. 3. Mean diameters of eggs and their oil globules produced by yellowtail brood fish at different spawning days, when fed diets containing various supplemental levels of astaxanthin. 
produced normal larvae $2.2,1.2$, and 3.4 times that of those obtained from the 0,20 , and 40-Astx groups, respectively. The supplementation levels of astaxanthin seemed to be optimal at around $30 \mathrm{mg}$ per $\mathrm{kg}$-diet, beyond which (40-Astx) returns diminished (Fig. 2). Moreover, the percentage of normal larvae obtained from brood fish fed SDP supplemented with 20 and $30 \mathrm{ppm}$ astaxanthin were higher than those obtained from brood fish fed SDP with or without krill meal supplementation in a previous study. ${ }^{5}$ This indicates the superiority of pure astaxanthin compared to krill meal.")

First-day of Spawning: In our previous study, ${ }^{1,2,5,16)}$ we found a general decline in the production and quality of the eggs of yellowtail as the spawning period advanced. Critically examining the spawning process induced by HCG injection and the chemical profile of the eggs, we could classify the spawning period into 3 phases: initial, middle and final; the initial phase, particularly the production on the first-day, was the best since the egg quality dropped during the subsequent days. The supplemental effect of astaxanthin in SDP on the spawning performance of yellowtail broodstock based on the data obtained on the first day of spawning is summarized in Table 6. Eggs produced per female brood fish were $699 \times 10^{3}, 318 \times 10^{3}$, $924 \times 10^{3}$, and $430 \times 10^{3}\left(87 \times 10^{3}, 38 \times 10^{3}, 116 \times 10^{3}\right.$, and $53 \times 10^{3}$ eggs $/ \mathrm{kg}$-female) when fed SDP supplemented with $0,20,30$, and $40 \mathrm{ppm}$ astaxanthin, respectively. Calculated based on the total eggs produced, the corresponding figures for the rates of buoyant eggs were 75.6, $81.0,82.5$, and $54.6 \%$; the fertilization rates were 70.3 , $64.8,77.1$, and $39.6 \%$; the rates of normal eggs were 69.1 , $66.1,70.1$, and $46.7 \%$; the rates of hatched larvae were $52.6,63.3,75.6$, and $34.8 \%$; the rates of normal larvae were $48.1,51.6,64.3$, and $29.8 \%$; and finally, the survival activity index values indicating larval health were 12.2, $8.4,21.9$, and 15.4 , respectively. Thus, the number of normal larvae produced by brood fish fed SDP containing 30 ppm astaxanthin were higher than those obtained from the others, the figures being $1.3,1.2$, and 2.2 times higher than those of the 0,20 , and 40-Astx groups, respectively. Therefore, the spawning performance when evaluated on the basis of the first-day production exhibited more clearly the superiority of the 30-Astx group.

\section{Appraisal of Artificial Insemination}

To confirm the results obtained from fish that were allowed to spawn spontaneously, the production from artificially inseminated eggs was compared. Milt and eggs were gently stripped 48 hours after the injection of HCG. The maturity of the eggs was confirmed prior to stripping because the ripeness may also be dependent on factors such as water temperature and fish size. ${ }^{17)}$ Table 7 shows the results obtained on artificial breeding of yellowtail brood fish fed SDP supplemented with astaxanthin at different levels for about 5 months prior to spawning. Three females of each test diet group were employed and the values were expressed as average numbers. Eggs produced per female brood fish were $505 \times 10^{3}, 414 \times 10^{3}$, $598 \times 10^{3}$, and $522 \times 10^{3}\left(71 \times 10^{3}, 48 \times 10^{3}, 81 \times 10^{3}\right.$, and $61 \times 10^{3}$ eggs $/ \mathrm{kg}$-female) when fed SDP supplemented with $0,20,30$, and $40 \mathrm{ppm}$ astaxanthin, respectively. The corresponding figures for the rates of buoyant eggs were $95.7,94.1,91.2$, and $83.0 \%$; the fertilization rates were $74.9,67.9,77.2$, and $61.0 \%$; and the rates of normal eggs were $81.9,83.1,83.7$, and $77.9 \%$, all calculations made in relation to total eggs produced. These values are similar to

Table 6. The first-day spawning performance of yellowtail broodstock fed SDP supplemented with different levels of astaxanthin

\begin{tabular}{|c|c|c|c|c|c|c|}
\hline \multirow{2}{*}{$\begin{array}{l}\text { Experimental } \\
\text { factors }\end{array}$} & & & \multicolumn{4}{|c|}{ Experimental groups } \\
\hline & & & 0-Astx & 20-Astx & 30-Astx & 40-Astx \\
\hline \multirow{2}{*}{\multicolumn{2}{|c|}{$\begin{array}{l}\text { Average BW of female } \\
\text { Number of spawners }\end{array}$}} & $(\mathrm{kg})$ & 8.00 & 8.26 & 7.97 & 8.12 \\
\hline & & (male:female) & $7: 7$ & $7: 7$ & $7: 7$ & $7: 7$ \\
\hline \multicolumn{7}{|l|}{ Eggs } \\
\hline \multirow[t]{2}{*}{ Eggs produced ${ }^{* 1}$} & & ( $\times 10^{3} /$ female $)$ & 699 & 318 & 924 & 430 \\
\hline & & $\left(\times 10^{3} / \mathrm{kg}\right.$-female $)$ & 87 & 38 & 116 & 53 \\
\hline Buoyancy rate & & $(\%)$ & 75.6 & 81.0 & 82.5 & 54.6 \\
\hline \multirow{2}{*}{ Fertilization rate among: } & -Total eggs produced & $(\%)$ & 70.3 & 64.8 & 77.1 & 39.6 \\
\hline & -Buoyant eggs & $(\%)$ & 93.0 & 80.0 & 93.5 & 72.5 \\
\hline \multirow{2}{*}{ Normal eggs ${ }^{*_{1}}$ among: } & - Total eggs produced & $(\%)$ & 69.1 & 66.1 & 70.1 & 46.7 \\
\hline & -Buoyant eggs & $(\%)$ & 91.5 & 81.5 & 85.0 & 85.5 \\
\hline \multirow{2}{*}{\multicolumn{2}{|c|}{$\begin{array}{l}\text { Egg diameter }{ }^{*_{1}} \\
\text { Oil-globule diameter }{ }^{* 1}\end{array}$}} & $(\mu \mathrm{m})$ & $1187 \pm 57$ & $1197 \pm 52$ & $1222 \pm 29$ & $1199 \pm 59$ \\
\hline & & $(\mu \mathrm{m})$ & $310 \pm 14$ & $321 \pm 11$ & $321 \pm 11$ & $330 \pm 10$ \\
\hline \multicolumn{7}{|l|}{ Larvae } \\
\hline \multirow[t]{3}{*}{ Rate of hatching among: } & -Total eggs produced & $(\%)$ & 52.6 & 63.3 & 75.6 & 34.8 \\
\hline & -Buoyant eggs & $(\%)$ & 69.6 & 78.1 & 91.7 & 63.8 \\
\hline & -Fertilized eggs & $(\%)$ & 74.8 & 97.6 & 98.1 & 88.0 \\
\hline \multirow{2}{*}{ Larvae obtained } & & $\left(\times 10^{3} /\right.$ female $)$ & 368 & 201 & 699 & 150 \\
\hline & & $\left(\times 10^{3} / \mathrm{kg}\right.$-female $)$ & 46 & 24 & 88 & 18 \\
\hline Survival activity index & & & 12.2 & 8.4 & 21.9 & 15.4 \\
\hline Normal larvae obtained ${ }^{*}$ & & $(\%)$ & 48.1 & 51.6 & 64.3 & 29.8 \\
\hline
\end{tabular}

\footnotetext{
"See the footnote of Table 5 .
} 
Table 7. Results of seed production on artificial insemination in yellowtail brood fish fed SDP supplemented with different levels of astaxanthin for about 5 months prior to spawning*1

\begin{tabular}{|c|c|c|c|c|c|c|}
\hline \multirow{2}{*}{$\begin{array}{l}\text { Experimental } \\
\text { factors }\end{array}$} & & & \multicolumn{4}{|c|}{ Experimental groups } \\
\hline & & & 0-Astx & 20-Astx & 30-Astx & 40-Astx \\
\hline \multicolumn{2}{|l|}{ Average BW of female } & (kg) & $7.27 \pm 1.01$ & $8.21 \pm 0.83$ & $7.43 \pm 1.36$ & $7.63 \pm 1.53$ \\
\hline \multicolumn{2}{|l|}{ Eggs } & & & & . & \\
\hline \multirow[t]{2}{*}{ Eggs produced } & & $\left(\times 10^{3} /\right.$ female $)$ & $505 \pm 227$ & $414 \pm 310$ & $598 \pm 215$ & $522 \pm 538$ \\
\hline & & ( $\times 10^{3} / \mathrm{kg}$-female $)$ & $71 \pm 33$ & $48 \pm 35$ & $81 \pm 27$ & $61 \pm 56$ \\
\hline Buoyancy rate & & $(\%)$ & $95.7 \pm 0.9$ & $94.1 \pm 22.4$ & $91.2 \pm 0.7$ & $83.0 \pm 4.4$ \\
\hline \multirow[t]{2}{*}{ Fertilization rate among: } & -Total eggs produced & (\%) & $74.9 \pm 9.2$ & $67.9 \pm 37.2$ & $77.2 \pm 4.8$ & $61.0 \pm 3.0$ \\
\hline & -Buoyant eggs & $(\%)$ & $78.2 \pm 10.0$ & $72.2 \pm 31.4$ & $84.7 \pm 5.9$ & $73.5 \pm 4.6$ \\
\hline \multirow[t]{2}{*}{ Normal eggs ${ }^{* 2}$ among: } & - Total eggs produced & $(\%)$ & $81.9 \pm 12.8$ & $83.1 \pm 33.3$ & $83.7 \pm 4.9$ & $77.9 \pm 9.0$ \\
\hline & -Buoyant eggs & $(\%)$ & $85.5 \pm 14.0$ & $88.3 \pm 19.3$ & $91.8 \pm 4.9$ & $93.8 \pm 7.8$ \\
\hline \multirow{2}{*}{\multicolumn{2}{|c|}{$\begin{array}{l}\text { Egg diameter }{ }^{* 2} \\
\text { Oil-globule diameter }{ }^{*}\end{array}$}} & $(\mu \mathrm{m})$ & $1203 \pm 41$ & $1189 \pm 42$ & $1200 \pm 20$ & $1180 \pm 31$ \\
\hline & & $(\mu \mathrm{m})$ & $311 \pm 8$ & $308 \pm 18$ & $306 \pm 8$ & $314 \pm 15$ \\
\hline \multicolumn{7}{|l|}{ Larvae } \\
\hline \multirow[t]{3}{*}{ Rate of hatching among: } & - Total eggs produced & $(\%)$ & $48.7 \pm 19.4$ & $64.5 \pm 40.0$ & $70.6 \pm 2.4$ & $29.1 \pm 6.3$ \\
\hline & -Buoyant eggs & $(\%)$ & $50.8 \pm 20.5$ & $68.6 \pm 35.9$ & $77.5 \pm 2.3$ & $35.1 \pm 8.8$ \\
\hline & -Fertilized eggs & (\%) & $65.0 \pm 18.9$ & $95.0 \pm 12.1$ & $91.5 \pm 8.0$ & $47.7 \pm 9.9$ \\
\hline \multirow[t]{2}{*}{ Larvae obtained } & & $\left(\times 10^{3} /\right.$ female $)$ & $246 \pm 188$ & $267 \pm 288$ & $422 \pm 151$ & $152 \pm 183$ \\
\hline & & $\left(\times 10^{3} / \mathrm{kg}\right.$-female $)$ & $33 \pm 21$ & $31 \pm 33$ & $57 \pm 20$ & $18 \pm 19$ \\
\hline Survival activity index & & & 13.9 & 15.1 & 17.8 & 18.3 \\
\hline Normal larvae obtained ${ }^{*_{2}}$ & & $(\%)$ & 41.6 & 57.0 & 64.9 & 27.3 \\
\hline
\end{tabular}

$*_{1}$ Mean $\pm S D, n=3$.

$*_{2}$ See the foomote of Table 5.

those obtained from spontaneous spawning, implying that the production was improved by the inclusion of astaxanthin in the diets up to $30 \mathrm{ppm}$, beyond which there was a notable reduction.

The above findings are corroborated when the evaluations are based on the larvae produced. The figures obtained from fish fed SDP supplemented with $0,20,30$, and $40 \mathrm{ppm}$ astaxanthin were $246 \times 10^{3}, 267 \times 10^{3}, 422 \times 10^{3}$, and $152 \times 10^{3}$ larvae/female $\left(33 \times 10^{3}, 31 \times 10^{3}, 57 \times 10^{3}\right.$, and $18 \times 10^{3}$ larvae/kg-female); and when expressed on the basis of total eggs produced the percentages of hatched larvae were $48.7,64.5,70.6$, and 29.1 and the rates of normal larvae were $41.6,57.0,64.9$, and $27.3 \%$, respectively. Interestingly, the figures for normal larvae obtained from artificial insemination were almost same as those obtained on the first day of spontaneous spawning in this study. This confirms the validity of the assessment of spawning performance and quality of eggs based on the first-day production in this species.

The observations made in this study have clearly indicated that the spawning performance and quality of eggs of yellowtail in terms of the rate of buoyant and fertilized eggs, number of hatched larvae, and especially the rate of normal larvae obtained, could be improved by the supplementation of pure astaxanthin in the diets for broodstock. The effectiveness of astaxanthin was in good agreement with the research of Watanabe et al. ${ }^{18)}$ on broodstock red sea bream. The optimal level of astaxanthin in the diets for yellowtail broodstock is thus suggested to be 30 $\mathrm{mg} / \mathrm{kg}$-diet, almost close to that recommended for red sea bream $(20 \mathrm{mg} / \mathrm{kg}$-diet $){ }^{19)}$ The slight difference may be species-specific, size-dependent, fecundity-based, spawning rhythm-oriented or utilization-related. Further studies of the chemical aspects could help us understand the metabolism and functions of this carotenoid.

Generally, researchers in Japan involved in yellowtail seed production, expect one female brood fish to produce about 1 million eggs, $50 \%$ of which should ultimately yield normal hatched larvae. Brood fish fed SDP supplemented with $30 \mathrm{ppm}$ astaxanthin for about 5 months prior to their spawning should be able to meet that demand. However, the effect of other carotenoid sources that can be freely converted to zeaxanthin and subsequently incorporated into yellowtail eggs, and that of other nutrients like vitamins $E$ and $C$, phospholipids, minerals, etc. on the spawning performance and quality of eggs of this species should also be examined to obtain further basic data necessary for the formulation of wholesome broodstock diets.

\section{References}

1) T. Watanabe, V. Verakunpiriya, T. Takeuchi, K. Mushiake, K. Kawano, and I. Hasegawa: The first spawn-taking from broodstock yellowtail cultured with extruded dry pellets. Fisheries Sci., 62, 388393 (1996).

2) V. Verakunpiriya, T. Watanabe, K. Mushiake, V. Kiron, S. Satoh, and T. Takeuchi: Effect of broodstock diets on the chemical components of milt and eggs produced by yellowtail. Fisheries Sci., 62, 610-619 (1996).

3) T. Fujita, M. Satake, S. Hikichi, M. Takeda, S. Shimeno, H. Kuwabara, W. Miki, K. Yamaguchi, and S. Konosu: Pigmentation of cultured yellowtail with krill oil. Nippon Suisan Gakkaishi, 49, 1595-1600 (1983).

4) T. Watanabe, A. Itoh, A. Murakami, Y. Tsukashima, C. Kitajima, and S. Fujita: Effect of nutritional quality of diets given to broodstock on the verge of spawning on reproduction of red sea bream. Nippon Suisan Gakkaishi, 50, 1023-1028 (1984).

5) V. Verakunpiriya, K. Watanabe, K. Mushiake, K. Kawano, T. Kobayashi, I. Hasegawa, V. Kiron, S. Satoh, and T. Watanabe: Effect of krill meal supplementation in soft-dry pellets on spawning 
and quality of eggs of yellowtail. Fisheries Sci., 63, 433-439 (1997).

6) K. Yamaguchi, W. Miki, N. Toriu, Y. Kondo, M. Murakami, S. Konosu, M. Satake, and T. Fujita: The composition of carotenoid pigments in the Antarctic krill Euphausia superba. Nippon Suisan Gakkaishi, 49, 1411-1415 (1983).

7) T. Watanabe, H. Sakamoto, M. Abiru, and J. Yamashita: Development of a new type of dry pellet for yellowtail. Nippon Suisan Gakkaishi, 57, 891-897 (1991).

8) H. Sakamoto, T. Watanabe, and T. Takeuchi: Optimal levels of protein and lipid in a newly developed soft-dry pellet for yellowtail, Seriola quinqueradiata. Suisanzoshoku, 43, 345-351 (1995).

9) S. Shimeno: Yellowtail, Seriola quinqueradiata, in "Handbook of Nutrient Requirements of Finfish" (ed. by R. P. Wilson), CRC Press, London, 1991, pp. 181-191.

10) T. Watanabe: Lipid nutrition in fish. Comp. Biochem. Physiol. 73B, 3-15 (1982).

11) J. R. Sargent: Origins and function of eggs lipids: Nutritional implication, in "Broodstock Management and Egg and Larval Quality" (ed. by N. R. Bromage and R. J. Roberts), University Press, Cambridge, Great Britain, 1995, pp. 353-372.

12) K. Mushiake, S. Arai, A. Mastumoto, H. Shimma, and I. Hasegawa: Artificial insemination from 2 year-old cultured yellowtail fed with moist pellets. Nippon Suisan Gakkishi, 59, 1721-1726 (1993).

13) K. Mushiake, H. Fujimoto, and H. Shimma: A trial of evaluation of activity in yellowtail Seriola quinqueradiata larvae. Suisan- zoshoku, 41, 339-344 (1993).

14) K. Mushiake, K. Kawano, W. Sakamoto, and I. Hasegawa: Effect of extended daylength on ovarian maturation and HCG-induced spawning in yellowtail fed moist pellets. Fisheries Sci., 60, 647-651 (1994).

15) W. Miki, K. Yamaguchi, and S. Konosu: Comparison of carotenoids in the ovaries of marine fish and shellfish. Comp. Biochem. Physiol., 71B, 7-11 (1982).

16) K. Mushiake, K. Kawano, V. Verakunpiriya, T. Watanabe, and I. Hasegawa: Egg collection from broodstocks of yellowtail fed commercial soft-dry pellets. Nippon Suisan Gakkishi, 61, 540-546 (1995).

17) W. Goetz: Hormonal control of oocyte final maturation and ovulation in fishes, in "Fish Physiology" Vol. IX, Part B (ed. by W. S. Hoar, D. I. Randall, and E. M. Donaldson), Academic Press, New York, 1983, pp. 117-170.

18) T. Watanabe, T. Fujimura, M-J. Lee, K. Fukusho, S. Satoh, and T. Takeuchi: Effect of polar and nonpolar lipids from krill on quality of eggs of red seabream Pagrus major. Nippon Suisan Gakkaishi, 57, 695-698 (1991).

19) T. Watanabe and W. Miki: Astaxanthin: An effective dietary component for red seabream broodstock, in "Fish Nutrition in Practice" (ed. by S. J. Kaushik and P. Luquet), INRA, Paris, 1993, pp. 27-36. 